\title{
FLORAL TRAITS AND POLLINATION OF SPANISH CHERRY (Mimusops elengi Linn.) IN UNIVERSITI MALAYSIA TERENGGANU CAMPUS
}

\author{
HAIKAL HAZMI SUKRI, FELICIA SYUPIE GUNONG, NAZURAH IDIN AND NOR ZALIPAH \\ MOHAMED*
}

Faculty of Science and Marine Environment, Universiti Malaysia Terengganu, 21030 Kuala Nerus, Terengganu

*Corresponding author: zalipah@umt.edu.my

http://doi.org/10.46754/umtjur.2021.07.005

\begin{abstract}
Some plants are self-compatible thus do not require pollinating agents for fertilisation of the ovule. Pollinating agents however are essential to promote cross-fertilisation, thus beneficial for the long-term survival of the plant species. In this study, we investigate the flower characteristics (flower size, colour, breeding system and nectar reward) and flower visitors of the Spanish cherry, Mimusops elengi, one of the most commonly planted ornamental trees in Universiti Malaysia Terengganu campus. Observations of flowers and the flower visitors were conducted between October 2016 and February 2017. The small sized flower, $19.88 \pm 1.70 \mathrm{~mm}$ (mean \pm SD) in height and 11.38 $\pm 0.87 \mathrm{~mm}$ (mean $\pm \mathrm{SD})$ in width; low volume with $11.90 \pm 5.55 \mu \mathrm{l}$ (mean $\pm \mathrm{SD})$ but with high sugar concentration with $26.57 \pm 3.72 \%$ (mean $\pm \mathrm{SD}$ ) nectar reward indicated insect pollination syndrome in this species. Xenogamy breeding system was determined for this species from the pollen-toovule ratio observation, which showed pollinating agents are required for cross-pollination to occur. Notes on the flower visitors revealed that two hymenopteran bee species, Xylocopa confusa and Heterotrigona itama as the pollinating agents of M. elengi. Not only these two species showed high visitation to the flowers, but they also land on the flowers to feed on the flower nectar, which could then potentially transfer the conspecific pollen grains on their bodies to the stigma for fertilisation of the flowers they visited.
\end{abstract}

Keywords: Xenogamy, Heterotrigona itama, Xylocopa confusa, visitation rate, conspecific pollen, landing

\section{Introduction}

Pollination is vital for the survival of plant species. Successful plant pollination occurs when pollen from the anther reach the stigma of the flower for fertilisation of the ovule. This pollen transfer could happen with the help of flower visitors that come to the flowers to feed on nectar or pollen grains. Not all flower visitors however are pollinating agents as during the feeding activity, they may also act as nectar robbers and flower predators (Inouye, 1980). While feeding, these flower visitors may act as pollinating agents depending on their feeding behaviours, visitation frequency and the number of pollen grains they carry on their bodies (Boyd, 2004; Reynolds \& Fenster, 2008). A reproductive success such as the quality and the quantity of fruit and seed set is influenced by the service of these pollinating agents. Apart from reducing the quality and quantity of fruit and seed set, a reduction of pollinators' service also promotes self-pollination in self-compatible plant species (Rodriguez-Perez, 2005).

Previous studies on Mimusops elengi Linn. (Spanish cherry) were conducted for the reason that this species has many medicinal and cultural values. For examples, the alcoholic extracts of $M$. elengi were found to enhances cognitive activity to prevent memory impairment (Hadaginhal et al., 2010), has a diuretic potential (Katedeshmukh et al., 2010), and contain antimicrobial producing agents against multidrug resistant microbes (Prakash et al., 2013). While from the cultural aspect, M. elengi is considered as a sacred plant by the Hindus (Mitra, 1981).

Although considered as a commonly found ornamental plant in Malaysia, to our knowledge, no study on the pollination of $M$. elengi was conducted, as compared to other highly valuable ornamental plants such as the orchids (Tan et al., 2002). Although the small sized flower is 
a characteristic of insect pollination syndrome (Willmer, 2011), on several occasions we observed small birds visiting the trees and sometimes feed on the flowers of $M$. elengi. Kamaruddin and Nor Zalipah (2020) found that the olive-backed sunbird visiting small size Ixora coccinae (jungle geranium) flowers in Universiti Malaysia Terengganu (UMT) campus might act as pollinating agents for the species with their large bodies which enable them to carry high pollen loads. Thus, we conducted this study on M. elengi, to further determine the role of flower visitors as pollinating agents for this plant species in UMT campus.

\section{Materials and Methods}

\section{Study Site and Species Studied}

This study was conducted at Universiti Malaysia Terengganu (UMT) campus in Kuala Nerus
District, located $25 \mathrm{~km}$ away from the city of Kuala Terengganu (Figure 1). Mimusop elengi from the Family Sapotaceea can be found in south and southeast Asia as well as in northern Australia. There are approximately 65 genera in the Family Sapotaceae, consisting of more than 800 species of evergreen trees and shrubs. In Malaysia, M. elengi is an ornamental plant, cultivated in gardens for its fragrant flowers and as a shade tree. It is a woody plant that can grow up to $15 \mathrm{~m}$ in height. The flower is star-shaped and is white (Figure 2). This small flower however produces sweet fragrance even when the flowers had finished blooming and have dried (Mitra, 1981). The leaves are variable in shape which include elliptic, oblong, short or long acuminate, margin undulate and closely but faintly veined. In UMT, the trees are commonly planted throughout campus, with the tree ranging between 1-8 $\mathrm{m}$ in height.

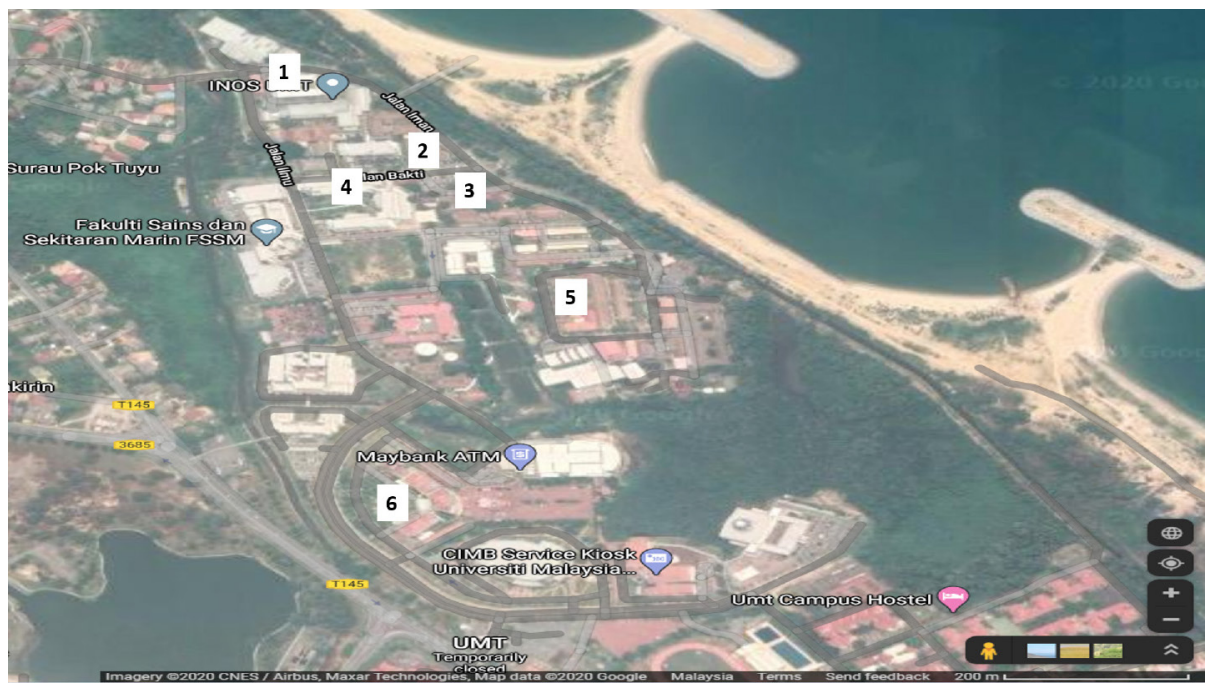

Figure 1: Location of sampling sites in Universiti Malaysia Terengganu (UMT) campus. 1) Makmal Biologi

Umum, 2) Bina Syarahan, 3) Rumah Universiti, 4) Kompleks Makmal Berpusat, 5) Pusat Pengajian Informatik dan Matematik Gunaan, 6) Canselori 


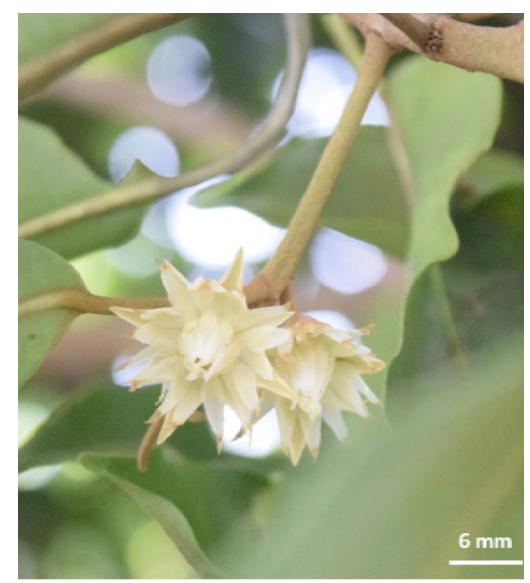

Figure 2: The flower of Mimusop elengi (Spanish cherry) in full bloom observed on a tree located near the Makmal Biologi Umum building

\section{Observations of Flowers}

Observations of flower characteristics were conducted between October and November 2016. For each observation, nine full bloom flowers were collected from three different trees (three flowers per tree) in the early morning before $1000 \mathrm{hr}$ and were brought to the laboratory for measurements (height and width) of the flower, stigma and anthers using a plastic vernier caliper. The height of the flower was measured from the base of its peduncle to the stigma. The width of the flower was measured from end-toend of the opposite petals of the open flower. After measurements of anthers and stigma, three anthers for each flower were collected and kept in the microcentrifuge tube containing 1.0 $\mathrm{ml}$ of $70 \%$ ethanol solution for future pollen count. The flowers were then dissected under a dissecting microscope attached with an eyepiece camera (Dino-eye AM 423X, Anmo Electronics Corporation, Taiwan) with 70x magnification for a maximum observation at $210 \mathrm{x}$ magnification. For each flower, the number of ovules was then recorded, and the size of the ovules measured from the photos captured using the Dino capture software.

To count the number of pollen grains, the microcentrifuge tubes containing the anthers were manually shaken to separate the pollen grains from the anthers, and $1.0 \mu$ l of the ethanol solution was then taken using a micropipette and put in a glass slide. The solution was then covered immediately with a coverslip to spread the pollen grain, before being observed under a light microscope attached with an eyepiece camera with a maximum observation of $2800 x$ magnification. For each flower, pollen counts were conducted for 10 slides and the total number of pollen grains was extrapolated for 1 $\mathrm{ml}$ of ethanol. Then, the number of pollen grains for a single anther was calculated by dividing the number of pollen grains with three anthers. The total number of pollen grains for the individual flower was estimated by multiplying the number of pollen grains per anther with the total number of anthers for the same flower. The pollen-ovule ratio of the flower was then calculated following Cruden (1977).

For the nectar standing crop, the selected flowers were bagged with a veil bag before its opening to avoid the nectar from being robbed by flower visitors (usually 2-3 days before flower opening). Then, the flowers were observed until its full bloom. To record the volume, nectar was extracted from the flower using $0.5 \mu \mathrm{l}$ glass capillary tube (Minicaps, 9000100, Hirschmann Laborgerate, Germany) at $1000 \mathrm{hr}$. To record the nectar sugar concentration, the flower nectar was extracted using $10 \mu \mathrm{l}$ micropipette. Then, the sugar concentration (sucrose in \% Brix) of the nectar was measured by using a digital sugar refractometer (HI 96801 Refractometer, Hanna Instruments Inc., USA). 


\section{Observations of Flower Visitors}

Observations of the flower visitors were conducted in October 2016 until February 2017. For this observation, a branch that encompasses approximately 10-15 flowers was selected for observation. A DSLR camera (NIKON D3300 with NIKON AF-S DX NIKKOR 18-55 mm lens) then was placed approximately $1 \mathrm{~m}$ from the selected flowers to record the visitation by the flower visitors. The recordings were conducted in three sessions: morning (0700$1000 \mathrm{hr}$ ), afternoon (1100-1400 hr) and evening (1500-1900 hr). For each observation hour, the recording was conducted only for the first 10 minutes. In total, observations were conducted on five different branches of five different trees, thus the total observation conducted was 650 $\mathrm{min} /$ tree. After observations, all flower visitors were caught using an insect net. The insects were later identified by referring to the insect collection at the UMT Insectarium.

The visitation frequencies of each flower visitors were determined from the video footage recorded. A visit was considered when a flower visitor is in close distance to the observed flowers (ca. 1-2 cm from the petals). Visits were recorded irrespective to previous visits by the flower visitors to the focal flower. The visitation behaviours were categorised into either landing or hovering to feed for nectar, or scouting. Landing is when the flower visitors come in contact with the flower by landing onto the flower, while hovering is when the visitors only hover near the flower (without coming into contact with the flower) to obtain nectar. Scouting is considered when the visitor flies close to the flower but did not attempt to feed on the flower. For landing and hovering, the time taken for each visitation was recorded from the time code of the footage. The time spent at the flower was recorded starting from when the visitor first approached the flower (ca. $1-2 \mathrm{~cm}$ distance from the flower) until it flies away.

The two most frequent flower visitors were captured using an insect net while visiting the flowers between $0900 \mathrm{hr}$ and $1300 \mathrm{hr}$.
Each of the captured visitors was then kept in individual plastic containers and euthanized with ethyl acetate to collect the pollen grains on their bodies. A needle was used to collect the individual pollen grains by rubbing the tip of the needle to the pollen basket (corbicula) of the captures, and the needle was then dipped into $1.0 \mathrm{ml}$ of $75 \%$ ethanol in a centrifuge tube to preserve the pollen grains for further observation. Observations on the pollen grains collected were conducted using the same procedure as for the pollen count for each flower. Pollen grains were grouped as either conspecific (M. elengi pollen grains) or heterospecific (other pollen grains).

\section{Data Analysis}

Chi-Square test was used to compare the total visitation frequency between the flower visitors, and to compare the number of behaviours (landing, hovering and scouting). MannWhitney tests were performed to compare the time spent between two flower visitors which showed landing and hovering behaviour respectively. Paired sample t-tests were conducted to determine the significant difference in the number of conspecific and heterospecific pollen grains for the two main flower visitors of M. elengi. All analyses were conducted using IBM SPSS ver. 20.0 (Chicago, USA) statistical software.

\section{Results and Discussion}

\section{Floral Traits}

The flower of M. elengi is small, which only about $20 \mathrm{~mm}$ in height and $11 \mathrm{~mm}$ width (Table 1). Each flower consists of a single stigma located in the middle of eight anthers. The ovary contains only two ovules, and each flower is estimated to have approximately 6786 pollen grains. The pollen-to-ovule $(\mathrm{P} / \mathrm{O})$ ratio was estimated to be $93392.89 \pm 3711.72$ (mean $\pm \mathrm{SD})$. Each flower produces approximately $12 \mu$ of flower nectar with about $26 \%$ sugar concentration. 
Table 1: Breeding characteristics of Mimusops elengi ( $\mathrm{n}=9$ flowers). Mean $\pm \mathrm{SD}$ is used throughout

\begin{tabular}{lcc}
\hline Variables & Result \\
\hline Number of anthers & 8 \\
Number of stigma & 1 \\
Number of ovules & 2 \\
Number of pollen per flower & $6785.78 \pm 7423.44$ \\
Pollen-to-ovule ratio & $93392.89 \pm 3711.72$ \\
Nectar volume $(\mu 1)$ & $11.90 \pm 5.55$ \\
Nectar sugar concentration $(\%)$ & $26.57 \pm 3.72$ \\
\hline & Height/Length (mm) & Width $(\mathrm{mm})$ \\
Flower size & $19.88 \pm 1.70$ & $11.38 \pm 0.87$ \\
Anther size & $3.22 \pm 0.26$ & $0.86 \pm 0.10$ \\
Stigma size & $0.56 \pm 0.09$ & $0.44 \pm 0.03$ \\
Ovule size & $0.68 \pm 0.11$ & $0.43 \pm 0.10$ \\
\hline
\end{tabular}

Flower characteristics such as the flower size and the reward offered (nectar) are essential factors in attracting pollinating agents to come to the flowers (Jacquenmart et al., 2015). However, some plants do not require pollinating agents for pollination by undergoing self-fertilisation (autogamy) in hermaphroditic flower (ie. flower that consists of male and female reproductive organs) (Martínez-Palle \& Aronne, 1999). For these self-compatible plants however, flower visitors may help to promote cross-pollination, thus, producing visually attractive floral displays and floral rewards is a way for animal-pollinated plants to promote the outcrossing breeding (Barrett, 2003; Goodwillie et al., 2010; Fisogni et al., 2011).

The white coloured and small sized flower of $M$. elengi indicate its strategy for insect pollination. Insects used ultraviolet light as a nectar guide to find the flowers as they could not detect the colour of the flowers (Cronk \& Ojeda, 2008). The bright coloured flowers which usually contain high amount of nectar on the other hand, are more favourable to be visited by birds (Van der Niet et al., 2015). The nectar produced by $M$. elengi consists mainly of sucrose component (Freeman et al., 1991), and the volume recorded in this study falls into the category of medium/ large bee-pollinated flowers (Willmer, 2011). The high quality and quantity of nectar produced influenced the visitation of insect pollinators to the flowers (Jacquemart et al., 2015).
The study of pollen and ovule within the flowers explained the mating mechanisms and breeding system of the plant (Cruden, 1977). Following the classification of plant breeding systems based on $\mathrm{P} / \mathrm{O}$ ratios, $M$. elengi is within the range of species showing xenogamy pollination $(>5000 \mathrm{P} / \mathrm{O}$ ratio). Xenogamy is cross-fertilisation that happened between different individual plants (Crawley, 1997). The group of the plants with xenogamy pollination usually requires the help of pollinating agents such as insect, bird and wind for pollination to occur. According to Barrett (2003) and Charlesworth (2006), the quantity and quality of offspring and consequently the movement of the genes in time and space depend on the reproductive strategies of the organism. Cross-fertilisation mating strategy is one of the strategies that are showed by many plants. However, because of natural selection during interaction with different pollination agents, the floral adaptation and reproductive strategies have evolved in the flowering plants (Barrett, 2010; Goodwillie et al., 2010). Therefore, the reproductive strategy depends on the form and function of the sexual units (stamens, pistils, flowers and/or inflorescences) that determine the pattern of pollen dispersal and receipt, together with post-pollination mechanisms such as genetically controlled incompatibility system (Barrett, 2003; 2010; Charlesworth, 2006). 


\section{Flower Visitors as Pollinators}

The visitors recorded were insects from the order Hymenoptera (four species) and Lepidoptera (one species), and a single species of bird, Cinnyris jugularis (olive-backed sunbird) (Table 2). Xylocopa confusa (carpenter bee) was recorded as the most frequent visitor with the total number of 149 visitations $\left(4.58 \times 10^{-2}\right.$ visit/ $\mathrm{min}$ ), followed by Heterotrigona itama (stingless bee) with the total number of 127 visitations (3.91 x $10^{-2}$ visit $\left./ \mathrm{min}\right)$. The lowest visitation was recorded from an unidentified butterfly (order Lepidoptera) with only six visitations (1.85 x $\left.10^{-3} \mathrm{visit} / \mathrm{min}\right)$.

Table 2: List of flower visitors and their visitation rate (visit/min) to the flowers. Number in parentheses indicates the number of visits (in \%) recorded by each flower visitors observed in the first 10 minutes of every observation hour

\begin{tabular}{llcc}
\hline Order & Famili & Species & Visitation rate \\
\hline Hymenoptera & Apidae & Xylocopa confusa & $4.58 \times 10^{-2}(38.5)$ \\
& & Heterotrigona itama & $3.91 \times 10^{-2}(32.7)$ \\
& & Unidentified wasp & $2.31 \times 10^{-2}(19.3)$ \\
Coleoptera & Cerambycidae & Unidentified long-horned beetle & $3.69 \times 10^{-3}(3.1)$ \\
Lepidoptera & - & Unidentified butterfly & $1.85 \times 10^{-3}(1.5)$ \\
Passeriformes* & Nectariniidae & Cinnyris jugularis & $5.85 \times 10^{-3}(4.9)$ \\
\hline
\end{tabular}

*Class Aves

Observations on the behaviour of the flower visitors showed that the majority of the visitations was by landing $(71 \%)$, and followed by hovering $(20 \%)$, while the least was for scouting with only $9 \%$ of the total visitations (Chi-Square test, ${ }^{2}=46.087, \mathrm{df}=2, \mathrm{p}<0.001$ ). The landing was observed only for $X$. confusa and $H$. itama, while hovering was recorded for unidentified wasp and butterfly (Table 3).
For landing, the time spent (mean $\pm \mathrm{SD}$ ) at the flowers recorded for $X$. confusa $(6.19 \pm 1.86$ sec) was significantly longer than $H$. itama $(5.26$ $\pm 1.80 \mathrm{sec})$ detected from the Mann-Whitney test conducted $\left(U=6.85 \times 10^{3}, \mathrm{p}<0.001\right)$. For hovering, unidentified butterfly $(5.17 \pm 1.47)$ was found to hover longer (Mann-Whitney test, $U=3.7210^{2}, \mathrm{p}<0.05$ ) at the flowers as compared to unidentified wasp $(3.51 \pm 0.84)$.

Table 3: Time spent (in sec) at the flowers (mean \pm SD) of the flower visitors with landing $\left(^{*}\right)$ and hovering $\left({ }^{* *}\right)$ behaviour while feeding at the flowers. $\mathrm{n}$ indicates the number of observations

\begin{tabular}{lccc}
\hline Visitor species & $\mathbf{n}$ & Time spent & Range \\
\hline Xylocopa confusa $^{*}$ & 149 & $6.19 \pm 1.86$ & $3-10$ \\
Heterotrigona itama $^{*}$ & 127 & $5.26 \pm 1.80$ & $2-10$ \\
Unidentified wasp $^{* *}$ & 75 & $3.51 \pm 0.84$ & $2-5$ \\
Unidentified butterfly $^{* *}$ & 6 & $5.17 \pm 1.47$ & $3-7$ \\
\hline
\end{tabular}

*For visitors with landing behaviour, time spent was significant at $\mathrm{p}=0.001$

${ }^{* *}$ For visitors with hovering behaviour, time spent was significant at $\mathrm{p}=0.05$

For the two most common flower visitors (Figure 3), the number (mean $\pm \mathrm{SD}$ ) of conspecific pollen grains on their bodies were doubled than that of the heterospecific grains observed (Table 4). The Paired sample t-tests conducted showed that the number of conspecific pollen grains was significantly higher than the heterospecific grains detected for both $X$. confusa $(\mathrm{t}=7.483$, $\mathrm{p}<0.001)$ and H. itama $(\mathrm{t}=8.419, \mathrm{p}<0.001)$. 

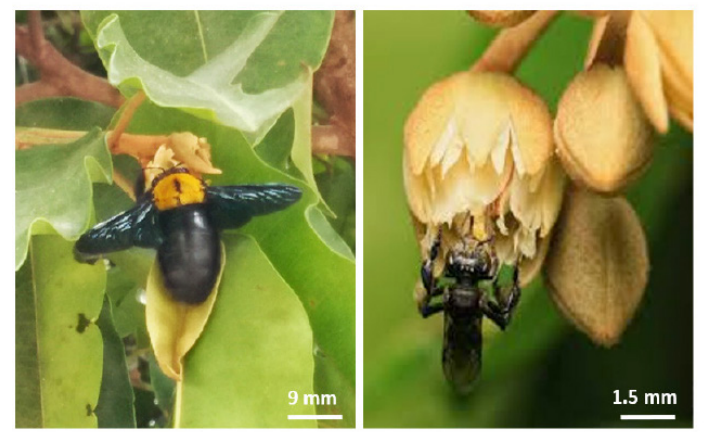

Figure 3: The two main flower visitors of Mimusop elengi in Universiti Malaysia Terengganu campus. A) Xylocopa confusa (carpenter bee), and B) Heterotrigona itama (stingless bee)

Table 4: Number of pollen grains (mean $\pm \mathrm{SD}$ ) recorded for the two main visitors of Mimusop elengi in Universiti Malaysia Terengganu campus. $n$ indicates the number of individuals observed

\begin{tabular}{lccc}
\hline Visitor species & $\mathbf{n}$ & Pollen type & Number of grains \\
\hline Xylocopa confusa & 8 & Conspecific & $12.00 \pm 3.29$ \\
& & Heterospecific & $4.00 \pm 1.77$ \\
Heterotrigona itama $^{*}$ & \multirow{2}{*}{} & Conspecific & $10.00 \pm 2.51$ \\
& & Heterospecific & $5.50 \pm 2.20$ \\
\hline
\end{tabular}

*Significant at $\mathrm{p}<0.001$

A favourable outcome in plant breeding from pollination is influenced by the number of pollinating agents (Martén-Rodríguez et al., 2015). The more individual visitors, the higher probability of successful fertilisation of the plants. Among insects; bees, wasps and occasionally ants (Order Hymenoptera), beetles (Order Coleoptera), moths and butterflies (Order Lepidoptera) and flies (Order Diptera) are among the most common pollinating agents for thousands of plant species (Dar et al., 2017). In our study, although only six species of flower visitors were recorded, high visitation frequencies particularly by two hymenopterans, $X$. confusa and $H$. itama showed their effectiveness as pollinating agents to the flowers they visited (Latif et al., 2019).

Landing on the flower is a common feeding strategy for many insects (Sarkar et al., 2014), as hovering feeding requires higher energy expenditure (Dreisig, 1997). Heterotrigona itama, with their small body size, enables them to land on small sized flowers to forage for nectar (Kamaruddin \& Nor Zalipah, 2020). Xylocopa confusa on the other hand, is relatively large as compared to $M$. elengi flower, thus landing feeding is more preferable to save their energy because they gain only a small amount of nectar from the flowers. The longer time is taken by this bee at the flowers however, probably to collect as much nectar as possible from the flowers to fulfil their energy demand. Hovering usually occurs in short duration at the flowers, not only to save energy but also could reduce exposure to predators (Romero et al., 2011).

Not all insect flower visitors are reliable pollinating agents because not all carry pollen grains on their bodies while foraging at the flowers (Gafni et al., 2018). As compared to the former two hymenopterans, an unidentified wasp and an unidentified butterfly only hovers at the flowers thus precluding them from acting as pollinating agents for the flowers. Although these two unidentified insects spent a considerable time foraging at the flowers, hovering from a distance limited them from collecting pollen grains from the flowers or transferring any pollen grains on their bodies to the stigma of the flower for pollination. Xylocopa confusa and $H$. itama on the other hand, carried a significantly higher number of conspecific pollen grains on their bodies, thus showing higher potentials for 
conspecific pollen transfer to the stigma of the flowers to initiate pollination.

\section{Conclusion}

Mimusops elengi found to show xenogamy breeding system which requires pollinating agents to undergo cross-pollination. The flower size and colour, together with the nectar reward further indicate its suitability for insects as pollinating agents. Although flowers were visited by six different insect species and a single nectarivorous bird species, only $X$. confusa and $H$. itama showed the highest potential as pollinating agents for M. elengi in UMT campus. Not only these two hymenopterans showed high visitation frequencies to the flowers, both species also carried higher amount of conspecific than heterospecific pollen grains on their bodies when visiting the flowers. Thus, while landing on the flowers to consume the nectar, these two hymenopterans could potentially transfer the conspecific pollen from their bodies to the stigma, further indicating their important role as pollinating agents to the plant species they forage at.

\section{Acknowledgements}

We would like to thank the Faculty of Science and Marine Environment for the equipment and logistic support while conducting this research, Associate Professor Dr Wahizatul Afzan Azmi for her help in identification of the insects, and Prof. Dato' Dr. Mohd Tajuddin Abdullah for his constructive comments on this article.

\section{References}

Barrett, S. C. H. (2003). Mating strategies in flowering plants: The outcrossing-selfing paradigm and beyond. Philosophical Transactions of the Royal Society B, 358, 991-1004.

Barrett, S. C. H. (2010). Understanding plant reproductive diversity. Philosophical Transactions of the Royal Society B, 365, 99-109.

Boyd, A. E. (2004). Breeding system of Macromeria viridiflora (Boraginaceae) and geographic variation in pollinators assemblages. The American Journal of Botany, 91, 1809-1813.

Cronk, Q., \& Ojeda, I. (2008). Bird-pollinated flowers in an evolutionary and molecular context. Journal of Experimental Botany, 59 (4), 715-727.

Charlesworth, D. (2006). Evolution of plant breeding systems. Current Biology, 16, 726735 .

Crawley, M. J. (1997). Plant ecology, $2^{\text {nd }}$ edition. Wiley-Blackwell, Oxford.

Cruden, R. W. (1977). Pollen-ovule ratios: A conservative indicator of breeding systems in flowering plants. Evolution, 31 (1), 3246.

Dar, S. A., Hassan. G. I., Padder, B. A., Wani, A. R., \& Parey, S. H. (2017). Pollination and evolution of plant and insect interaction. Journal of Pharmacognosy and Phytochemistry, 6(3), 304-311.

Dreisig, H. (1997). Why do some nectar foragers perch and others hover while probing flowers? Evolutionary Ecology, 11(5), 543555.

Fisogni, A., Cristololini, G., Rossi, M., \& Galloni, M. (2011). Pollinator directionality as a response to nectar gradient: Promoting outcrossing while avoiding geitonogamy. Plant Biology, 13, 848-856.

Freeman. E. C., Worthington, R. D., \& Jackson, M. S. (1991). Floral nectar sugar compositions of some south and southeast Asian species. Biotropica, 23(4), 568-574.

Gafni, A., Bohman, B., Quarrell, S. R., Brown, P. H., \& Allen, G. R. (2018). Frequent insect visitors are not always pollen carriers in hybrid carrot pollination. Insect, 9(2), doi: 10.3390/insects9020061.

Goodwillie, C., Sargent, R. D., Eckert, C. G., Elle, E., Geber, M. A., Johnston, M. O., Kalisz, S., Moeller, D. A., Ree, R. H., Vallejo-Marin, M., \& Winn, A. A. (2010). Correlated evolution of mating system and 
floral display traits in flowering plants and its implication for the distribution of mating system variation. New Phytologist, 185, 311-321.

Hadaginhal, R. V., Tikare, V. P., Patil, K. S., Bhanushali, M. D., Desai, N. S., \& Karigar, A. (2010). Evaluation of cognitive enhancing activity of Mimusops elengi Linn on albino rats. International Journal of Research in Ayurveda and Pharmacy, 1(2), 484-492.

Inouye, D. W. (1980). The terminology of floral larceny. Ecology, 61, 1251-1253.

Jacquemart, A. L., Somme, L. L., Colin, C., \& Quinet, M. (2015). Floral biology and breeding system of Impatients balfourii (Balsaminaceae): An exotic species in extension in temperate area. Flora, 214, 7075.

Kamaruddin, F., \& Nor Zalipah, M. (2020). Observation of flower visitors to determine their potential role as pollinators of Ixora coccinae and Reullia simplex. Universiti Malaysia Terengganu Journal of Undergraduate Research, 2 (1), 61-70.

Katedeshmukh, R. G., Shete, R. V., Otari, K. V., Bagade, M. Y., \& Pattewar, A. (2010). Acute toxicity and diuretic activity of Mimusops elengi extracts. International Journal of Pharma and Biosciences, 1(3), 1-6.

Latif, A., Malik, S. A., Saeed, S., Zaka, S. M., Sarwar, Z. M., Ali, M., Azhar, M. F., Javaid, M., Isthtiaq, M., Naeem-Ullah, U., Naoreen, M., Khan, K. A., Ghramh, H. A., \& Shahzad, M. A. (2019). Pollination biology of Albizia lebbeck (L.) Benth. (Fabaceae: Mimosoideae) with reference to insect floral visitors. Saudi Journal of Biological Sciences, 26, 1548-1552.

Martén-Rodríguez, S., Quesada, M., Castro, A. A., Lopezaraiza-Mikel, M., \& Fenster, B. C. (2015). A comparison of reproductive strategies between island and mainland Carribean Gesneriaceae. Journal of Ecology, 103, 1190-1204.
Martínez-Palle, E., \& Aronne, G. (1999). Flower development and reproductive continuity in Mediterranean Ruscus aculeatus L. (Liliceae). Protoplasma, 208, 58-64.

Mitra, R. (1981). Bakula a reputated drug Ayurveda, its history, uses in Indian medicine. Indian Journal History Science, 16 (2), 169-180.

Prakash, P., Gnanaprakasam, P., Emmanuel, R., Arokiyaraj, S., \& Saravanan, M. (2013). Green synthesis of silver nanoparticles from leaf extract of Mimusops elengi Linn. for enhanced antibacterial activity against multi drug resistant clinical isolated. Colloids and Surfaces B: Biointerfaces, 108, 255-259.

Reynolds, R. J., \& Fenster, C. B. (2008). Point and interval estimation of pollination importance: A study using pollinating data of Silene caroliniana. Oecologia, 156, 325332.

Rodriguez-Perez, J. (2005). Breeding system, flower visitors and seedling survival of two endangered species of Helianthemum (Cistaceae). Annals of Botany, 95, 12291236.

Romero, G. Q., Antiqueira, P. A. P., \& Koricheva, J. (2011). A meta-analysis of predation risk effects on pollinator behaviour. PLOS ONE, 6(6), e20689.

Sarkar, S., Nandy, A., \& Talapatra, S. N. (2014). Ethological study of flower visiting insects in two parks, Kolkata, India. International Letters of Natural Sciences, 12(1), 41-54.

Tan, K. H., Nishida, R., \& Toong, Y. C. (2002) Floral synomone of a wild orchid, Bulbophyllum cheiri, lures Bactrocera fruit flies for pollination. Journal of Chemical Ecology, 28 (6), 1161-1172.

Van der Niet, T., Cozien, R. J., \& Johnson, S. D. (2015). Experimental evidence for specialized bird pollination in the endangered South African orchid Satyrium rhodanthum and analysis of associated floral traits. Botanical Journal of the Linnean Society, 177 (1), 141-150. 
Willmer, P. (2011). Pollination and floral ecology. Princeton University Press, New Jersey. 